DOI: https://doi.org/10.36502/2019/droa.6150

\title{
Diabetes and Chronic Inflammation for Future Research Development
}

Hiroshi Bando ${ }^{1,2}$

${ }^{1}$ Tokushima University / Medical Research, Tokushima, Japan

${ }^{2}$ Japan Low Carbohydrate Diet Promotion Association, Kyoto, Japan

Corresponding Author: Hiroshi Bando, MD, PhD, FACP

Address: Tokushima University /Medical Research, Nakashowa 1-61, Tokushima-770-0943, Japan; E-mail: pianomed@bronze.ocn.ne.jp

Received date: 15 August 2019; Accepted date: 17 August 2019; Published date: 26 August 2019

Citation: Bando H. Diabetes and Chronic Inflammation for Future Research Development. Diab Res Open Access. 2019 Aug 26;1(1):1-4.

Copyright (C) 2019 Hiroshi Bando. This is an open-access article distributed under the Creative Commons Attribution License, which permits unrestricted use, distribution, and reproduction in any medium, provided the original work is properly cited.

\section{Keywords}

Diabetes Research: Open Access (DROA); Non-Communicable Diseases (NCDs); Lifestyle-Related Diseases; Damage-Associated Molecular Patterns (DMAPs); Chronic Inflammation; Adipose Tissue

\section{Editorial}

Congratulations on the inaugural issue of Diabetes Research: Open Access (DROA). Across the world, the necessity of medical practice and research concerning diabetes has been more emphasized. The significant role of this journal will be expected from now.

In recent years, lifestyle-related diseases such as obesity and diabetes have increased worldwide as non-communicable diseases (NCDs). Statistically, 71\% of 57 million world deaths in 2016 were from NCDs [1]. The United Nations meeting on NCSs reviewed the global progress for the prevention and control of NCDs, and proposed countdown 2030 for reduction of the burden of NCDs [1]. Among NCDs, diabetes and hypertension have been prevalent and important to manage in the clinical practice [2].

On the other hand, various problems concerning cancer have been also important. It is said that the prevalence of cancer is generally higher in patients with obesity and diabetes mellitus [3]. The burden of cancer attributable to obesity, expressed as population attributable fraction is $11.9 \% / 13.1 \%$ in men/women. [3].
As mentioned above, the mechanisms of chronic inflammation are common in both lifestyle-related diseases and cancer. Metabolic syndrome would be one of the major onsets of lifestyle-related diseases such as cardiovascular disease, diabetes, and dyslipidemia. The crucial point is the inflammation. In the visceral adipose tissue associated with obesity, chronic inflammation is present on the basis. Furthermore, it seems to be involved in the pathophysiology of lifestyle-related diseases and to promote the developing throughout the body [4]. In other words, each lifestyle habit such as overeating or lack of exercise can cause obesity and chronic inflammation in adipose tissue.

On the other hand, another important factor would be the aging mechanism along the natural course of the human. With the process of aging, there is a similar finding to the chronic inflammation observed in the adipose tissue. There are macrophages and lymphocytes, which are immune cells that infiltrate the adipose tissue. They have changed their traits to promote the inflammatory process, leading to the pathogenesis of lifestyle-related disease [4]. As described above, the pathology involves two mechanisms, which are chronic inflammation and aging. 


\section{Editorial}

Metabolism and the immune system always interact with each other. The presence of immune response will bring the onset of the inflammation, which affects the control of metabolism. Conversely, metabolic changes alter the inflammatory response. This close mutual influence can maintain various homeostasis of the human body. This failure may lead to the development of lifestyle-related diseases and the onset of cancer.

From the histological point of view, obesity shows the presence of the inflammatory response in the adipose tissue. Specifically, monocyte-derived proinflammatory macrophages (M1) and CD8 + T cell infiltration increase in adipose tissue [5]. As a result, the ratios of inflammation converging macrophages (M2), CD4 + T cells, and eosinophils are relatively decreased. This mechanism has been involved in the immune function of various organs [6]. In obesity, muscle inflammation also occurs as a result of immune cell infiltration and activation [7]. Then, subsequent myocyte metabolic alteration may lead to insulin resistance development [7].

When inflammation occurs in adipose tissue, its function will be affected. For example, various inflammatory cytokines, TNF- $\alpha$, can inhibit insulin signaling, promote lipolysis, and increase the amount of free fatty acids [8]. Recently, Palmitoleic acid has been in focus for increasing fatty acid oxidation in white adipocytes [9]. High levels of free fatty acids are known to correlate with the onset of heart death and type-2 diabetes, and diets rich in saturated fatty acids (SFA) are also associated with the onset of type 2 diabetes and coronary artery disease [10]. SFA induced insulin resistance, endotoxemia and significantly increased harmful plasma ceramides. Furthermore, SAT increases lipolysis, while unsaturated fatty acids decrease lipolysis [11].

The pathophysiological process leading to diabetes has been known. As the inflammation occurs in adipose tissue, the metabolism for lipolysis would be enhanced [12]. Then, increased free fatty acid (FFA) in the blood can cause inflammatory changes in the pancreas [13]. Furthermore, pro-inflammatory macrophages infiltrate in the islets, leading to impaired cell function. As a result, insulin secretion will be gradually reduced, and diabetic status will be merged.

From the viewpoint of basic medicine, the Inflammation has been a typical biodefense response to various internal and external stresses. Essentially, it is a protective and adaptive response for the body. It has been classified into some situations due to different causes.

The first is acute inflammation. This is induced by microbial infection or some wounds. The characteristics are four typical biodefense reactions. They are fever, redness, pain, and swelling, which have been well-known as four factors for the presence of the inflammation. These often converge transiently and return back to the previous healthy state when the peak of the inflammatory response has been subsided.

Second is chronic inflammation, which is observed in lifestyle-related diseases and metabolic syndrome [14]. The characteristic is that it does not show four characteristics of inflammation. On the other hand, low level of inflammatory condition has been persisting for long. Actually, there are persisting higher C-reactive protein (CRP) levels in patients with obesity and lifestyle diseases and also in animal models. It is known that mild inflammation persists throughout the body. These mild inflammatory responses can lead to tissue function modulation, organ damage, and irreversible organ dysfunction due to tissue remodeling.

Regarding lifestyle-related diseases, a lot of factors related to persisting inflammation have been considered to be non-infectious (aseptic inflammation). For example, enteric bacteria withdrawal products also contribute to the initiation and persistence of these natural inflammations [15]. Furthermore, it is recently proposed that mitochondrial damage-associated molecular patterns (DMAPs) are involved in chronic inflammatory situations [16]. 


\section{Editorial}

For the pathogenesis of chronic inflammatory disorders, mitochondria shows crucial role. When the mitochondrial physiology has been perturbed, dysfunctional mitochondria may instigate or propagate inappropriate and persistent inflammation. Its mechanism is proceeded by some factors, including inflammasomes activation, dysregulation of immune signaling, alteration of immunometabolism and the release of mitochondrial DAMPs. Consequently, it leads to some chronic inflammatory disorders in affected organs or systematically.

In summary, this article revealed the relationship between chronic inflammation, adipose tissue and lifestyle-related diseases such as obesity and diabetes. I hope the description would become a useful reference in diabetic research from now.

\section{References}

[1] Bennett JE, Stevens GA, Mathers CD, Bonita R, Rehm J, Kruk ME, Riley LM, Dain K, Kengne AP, Chalkidou K, Beagley J, Kishore SP, Chen W, Saxena S, Bettcher IW, Grove JT, Beaglehole R, Ezzati M. NCD Countdown 2030: worldwide trends in non-communicable disease mortality and progress towards Sustainable Development Goal target 3.4. Lancet. 2018 Sep 22;392(10152):1072-1088. [PMID: 30264707]

[2] Jayanna K, Swaroop N, Kar A, Ramanaik S, Pati MK, Pujar A, Rai P, Chitrapu S, Patil G, Aggarwal P, Saksena S, Madegowda H, Rekha S, Mohan HL. Designing a comprehensive Non-Communicable Diseases (NCD) programme for hypertension and diabetes at primary health care level: evidence and experience from urban Karnataka, South India. BMC Public Health. 2019 Apr 16;19(1):409. [PMID: 30991978]

[3] Avgerinos KI, Spyrou N, Mantzoros CS, Dalamaga M. Obesity and cancer risk: Emerging biological mechanisms and perspectives. Metabolism. 2019 Mar; 92:121-135. [PMID: 30445141]

[4] Shaw AC, Goldstein DR, Montgomery RR. Agedependent dysregulation of innate immunity. Nat Rev Immunol. 2013 Dec;13(12):875-87. [PMID: 24157572]

[5] Nishimura S, Manabe I, Nagasaki M, Eto K, Yamashita H, Ohsugi M, Otsu M, Hara K, Ueki
K, Sugiura S, Yoshimura K, Kadowaki T, Nagai R. $\mathrm{CD} 8+$ effector $\mathrm{T}$ cells contribute to macrophage recruitment and adipose tissue inflammation in obesity. Nat Med. 2009 Aug;15(8):914-20. [PMID: 19633658]

[6] Ahmed F, Ibrahim A, Cooper CL, Kumar A, Crawley AM. Chronic Hepatitis C Virus Infection Impairs M1 Macrophage Differentiation and Contributes to CD8+ T-Cell Dysfunction. Cells. 2019 Apr 25;8(4). pii: E374. [PMID: 31027182]

[7] Domingues-Faria C, Goncalves-Mendes N, Farges MC. Muscle Immune Cells, Obesity, and High-Fat Feeding. Nutrition and Skeletal Muscle. 2018 Nov 2; Chapter 10:125-135.

[8] Gregor MF, Hotamisligi GS. Inflammatory mechanisms in obesity. Annu Rev Immunol. 2011; 29:415-45. [PMID: 21219177]

[9] Cruz MM, Lopes AB, Crisma AR, de Sá RCC, Kuwabara WMT, Curi R, de Andrade PBM, AlonsoVale MIC. Palmitoleic acid (16:1n7) increases oxygen consumption, fatty acid oxidation and ATP content in white adipocytes. Lipids Health Dis. 2018 Mar 20; 17(1):55. [PMID: 29554895]

[10] Suiter C, Singha SK, Khalilli R, Shariat-Madar Z. Free Fatty Acids: Circulating Contributors of Metabolic Syndrome. Cardiovasc Hematol Agents Med Chem. 2018;16(1):20-34. [PMID: 29804539]

[11] Luukkonen PK, Sädevirta S, Zhou Y, Kayser B, Ali A, Ahonen L, Lallukka S, Pelloux V, Gaggini M, Jian C, Hakkarainen A, Lundbom N, Gylling H, Salonen A, Orešič M, Hyötyläinen T, Orho-Melander M, Rissanen A, Gastaldelli A, Clément K, Hodson L, Yki-Järvinen H. Saturated Fat Is More Metabolically Harmful for the Human Liver Than Unsaturated Fat or Simple Sugars. Diabetes Care. 2018 Aug;41(8):1732-1739. [PMID: 29844096]

[12] Morigny, P, Houssier, M, Mouisel, E, Langin, D. Adipocyte lipolysis and insulin resistance. Biochimie. 2016 Jun;125:259-66. [PMID: 26542285]

[13] Lytrivi M, Igoillo-Esteve M, Cnop M. Inflammatory stress in islet $\beta$-cells: therapeutic implications for type 2 diabetes?. Curr Opin Pharmacol. 2018 Dec;43:40-45. [PMID: 30142486]

[14] Reddy P, Lent-Schochet D, Ramakrishnan N, McLaughlin M, Jialal I. Metabolic syndrome is an inflammatory disorder: A conspiracy between adipose tissue and phagocytes. Clin Chim Acta. 2019 Sep; 

Aug 26;1(1):1-4.

\section{Editorial}

496:35-44. [PMID: 31229566]

[15] Belkaid Y, Hand TW. Role of the microbiota in immunity and inflammation. Cell. 2014 Mar 27; 157(1):121-41. [PMID: 24679531]

[16] Dela Cruz CS, Kang MJ. Mitochondrial dysfunction and damage associated molecular patterns (DAMPs) in chronic inflammatory diseases. Mitochondrion. 2018 Jul; 41:37-44. [PMID: 29221810] 